\title{
Structural Nanocomposites for Aerospace Applications
}

NASAOrbital ATK Technical Interchange Meeting

Mia Siochi

May 19, 2015
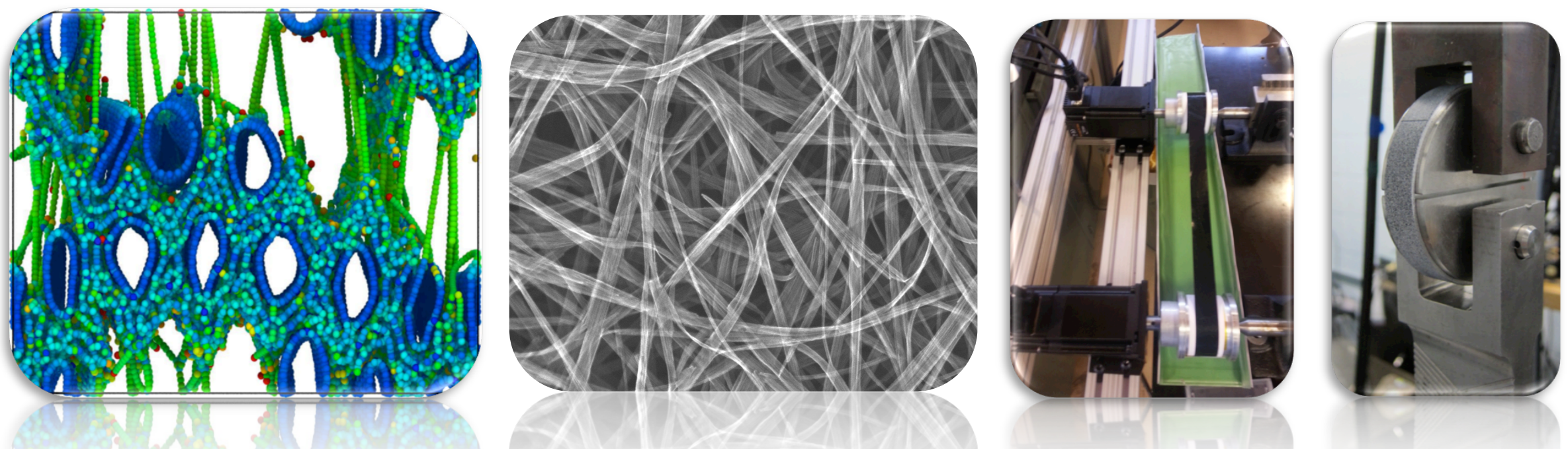


\section{NASA Structural GNT Team}

Langley Research Center

- Computational Materials

* NASA LaRC

* Kris Wise

* Ben Jensen

* Universities

* Greg Odegard - MTU

* Adri van Duin - PSU

- Synthesis

* NASA GRC

* Sandi Miller

* Tiffany Williams

* Marisabel Lebron-Colon

* James Baker

* NASA LaRC

* John Connell

* Joe Smith

* Yi Lin

* Material Suppliers

* Nanocomp Technologies

* General Nano

* Universities

* University of Cincinnati

* Rice University
- Processing

* nasa laRC

* Brian Grimsley

* Bert Cano

* Dennis Working

* Sean Britton

* Hoa Luong

* Jae-Woo Kim

- Godfrey Sauti

* NASA GRC

* Sandi Miller

* Tiffany Williams

* Universities

* FSU

* University of Cincinnati
- Materials Characterization/ Testing

* NASA laRC

* Buzz Wincheski

- Mike Czabaj

- James Ratcliffe

- Jae-Woo Kim

- Yi Lin

* Godfrey Sauti

* Jennifer Carpena

- Structural Mechanics \& Design * NAsa laRC

* Steve Scotti

- Systems Analysis

- NAsa laRC

* Mark McMillin 


\section{Why Structural Nanomaterials?}

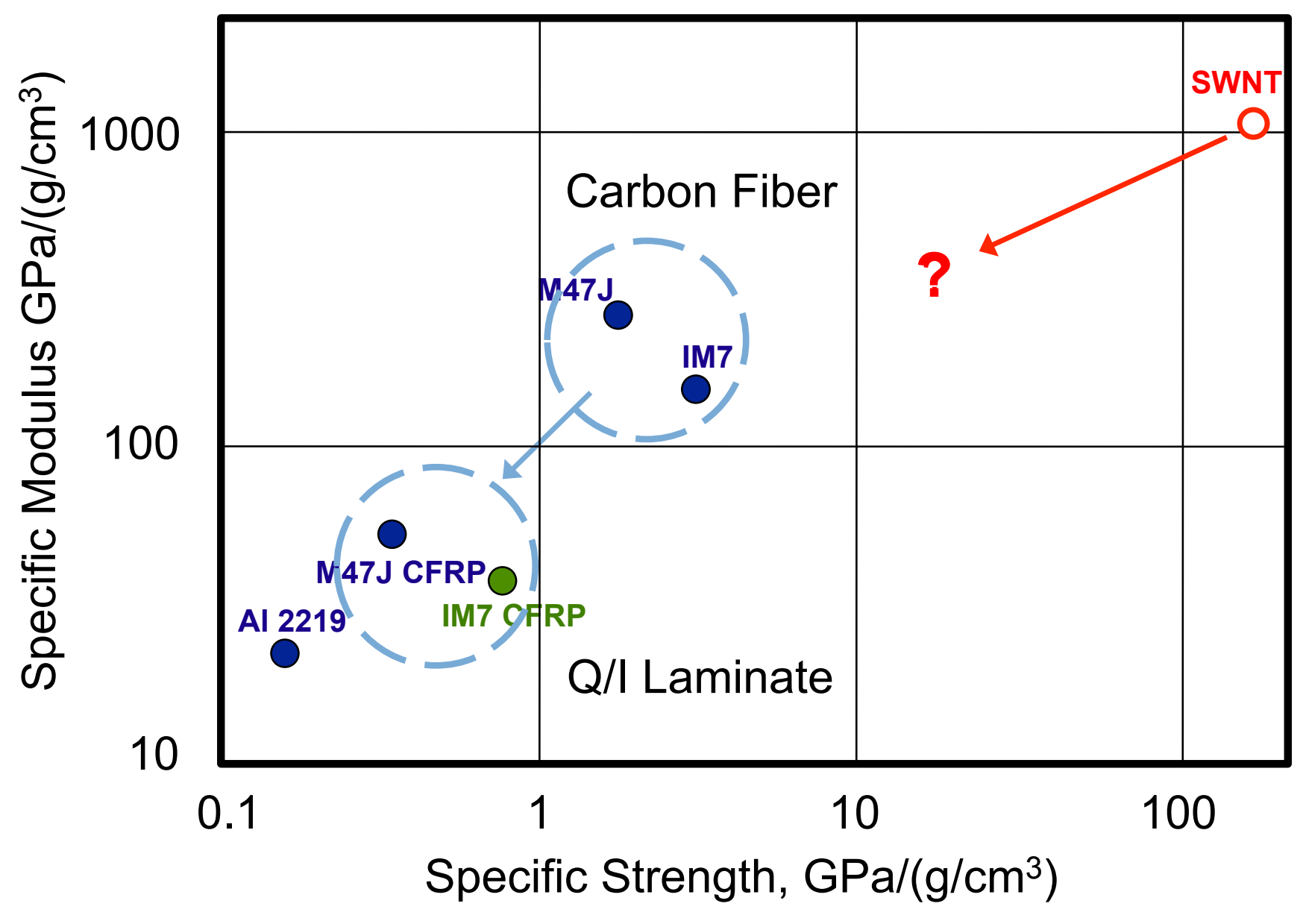




\section{Highlights from Early Workf $1999-2008$ NASA}

Langley Research Center
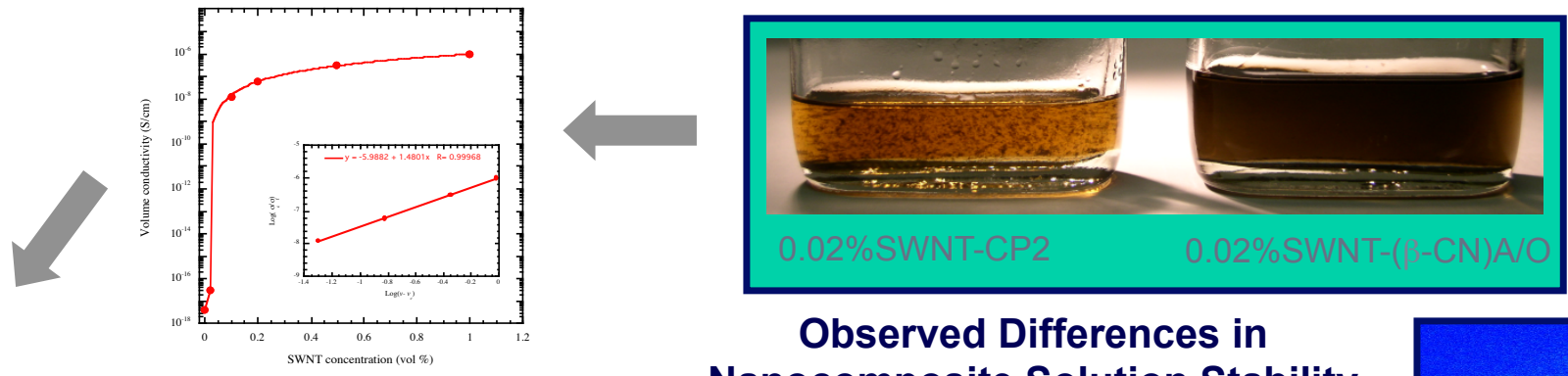

Observed Differences in Nanocomposite Solution Stability

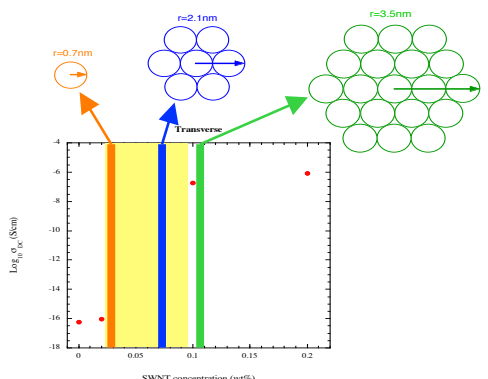

Measured Electrical Conductivity and Percolation Modeling
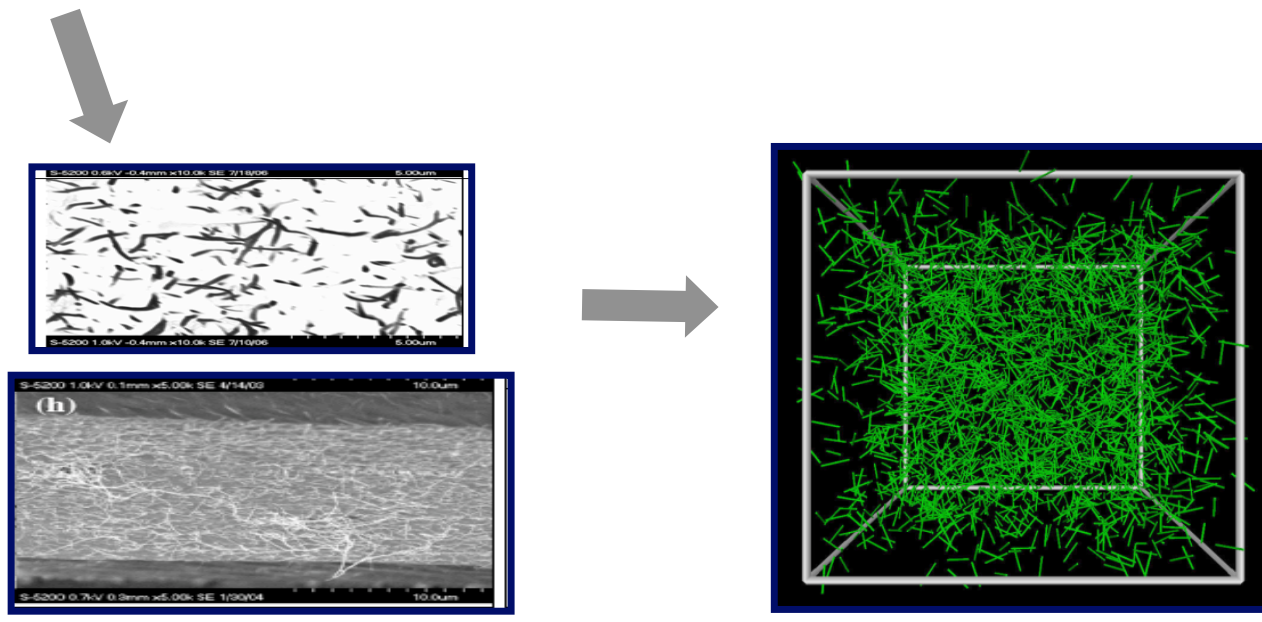

Fast Fourier Transform of HRSEM Image

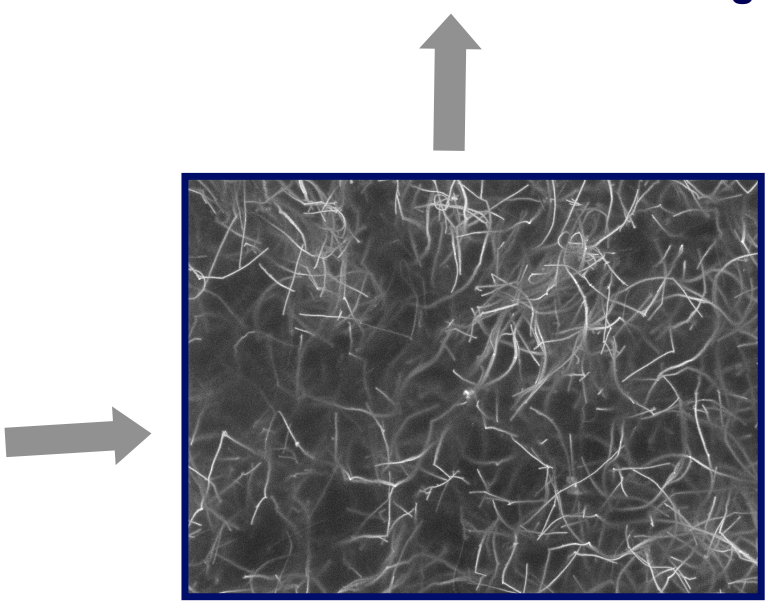

“Poly-transparent” Imaging 


\section{Potential System Weight Savings}

\section{Two Stage to Orbit Launch Vehicle Concept}

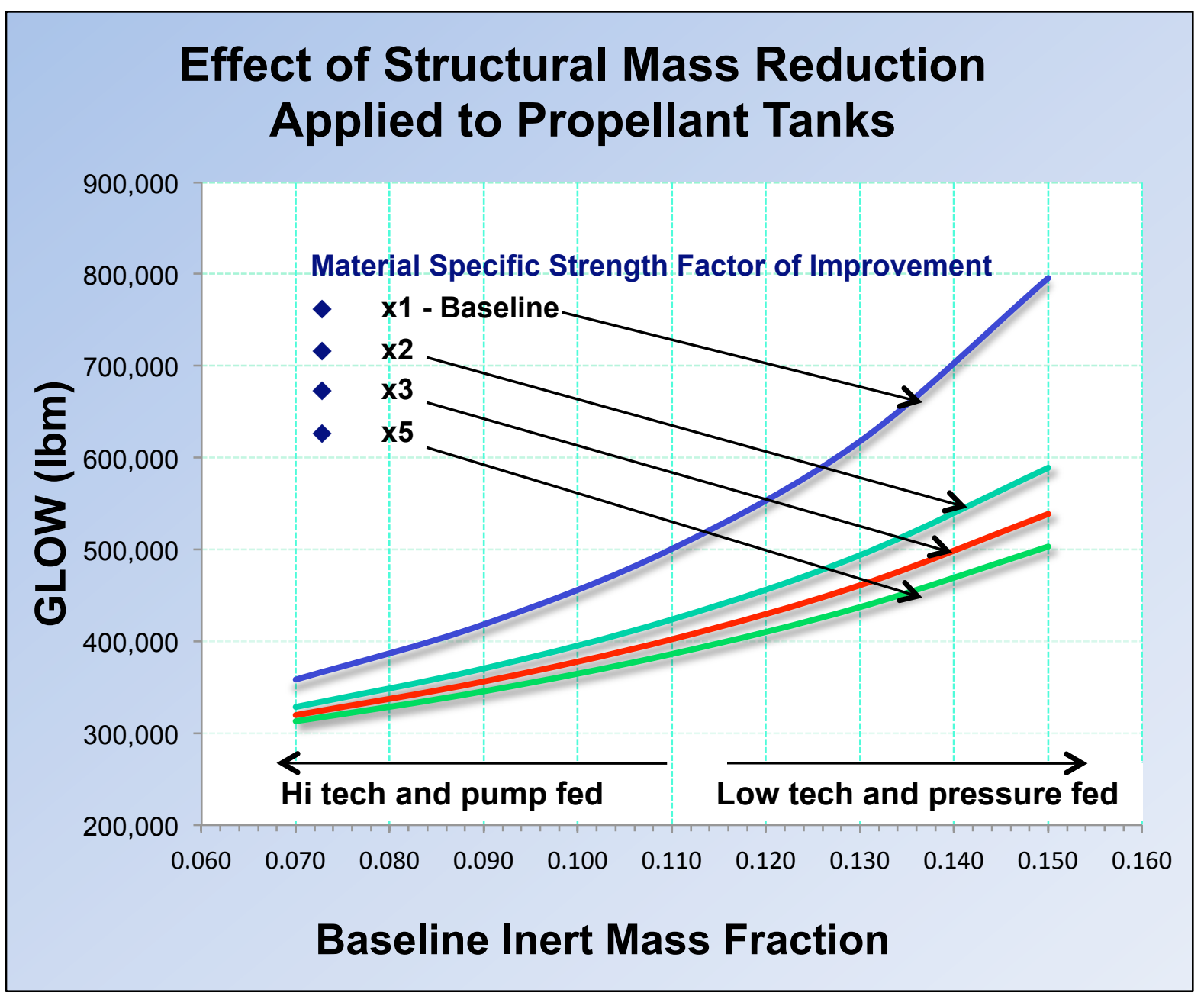

$>$ Baseline Mass Fractions typical for existing cryogenic pump and pressure fed stages

> Weight savings applied to pressurized structures only

$>$ Including other structures and subsystems may show increased benefit

$>$ Low tech pressure fed systems show greatest benefit from reduced structures weight 


\section{Nanotechnology Project Spans Modeling toma Component Demo}

Langley Research Center

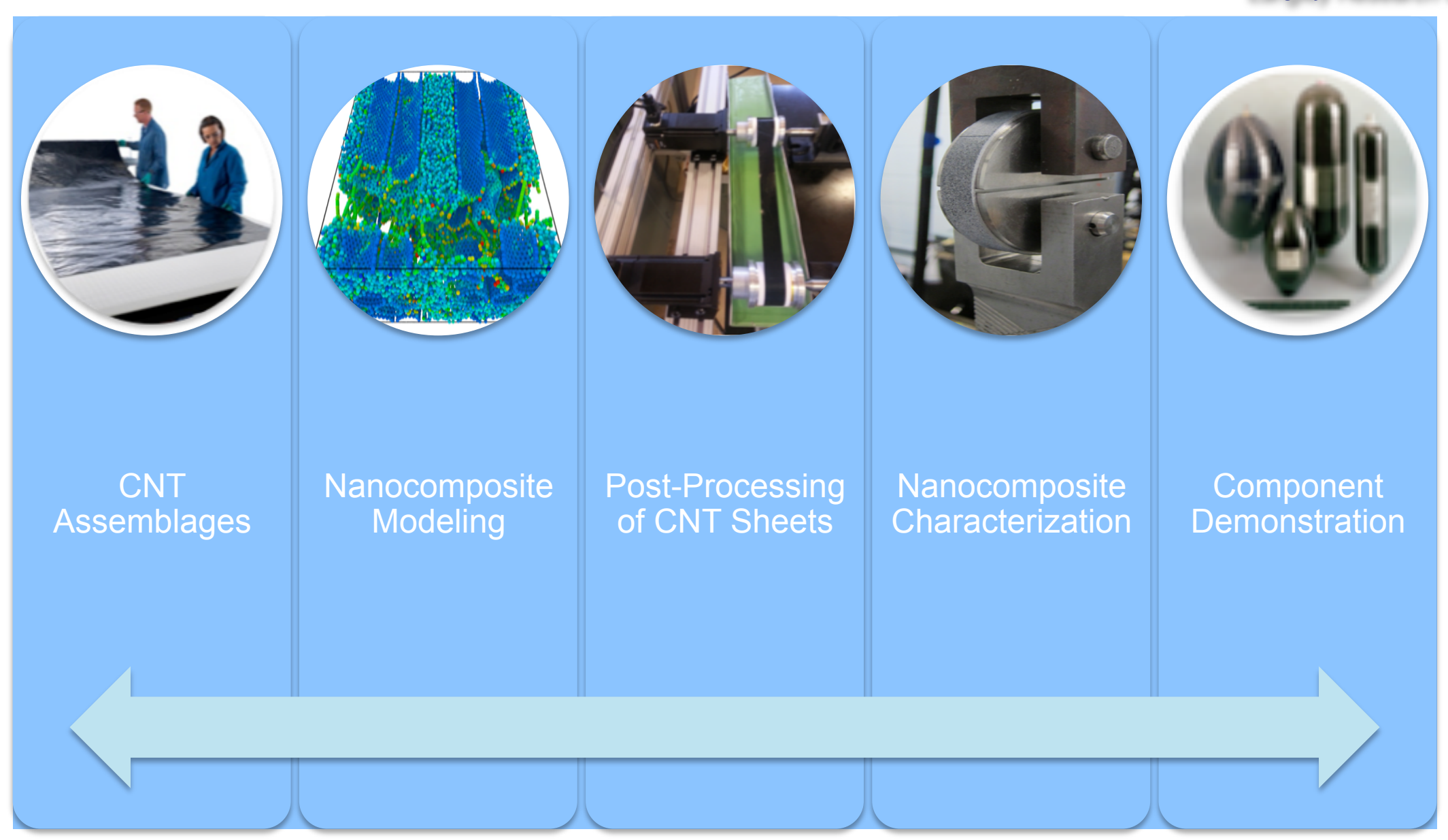

Project has adopted a comprehensive approach involving modeling, materials development, testing and characterization, and component level demonstration to accelerate materials development and mission transition 


\section{Materials SOA}

NASA
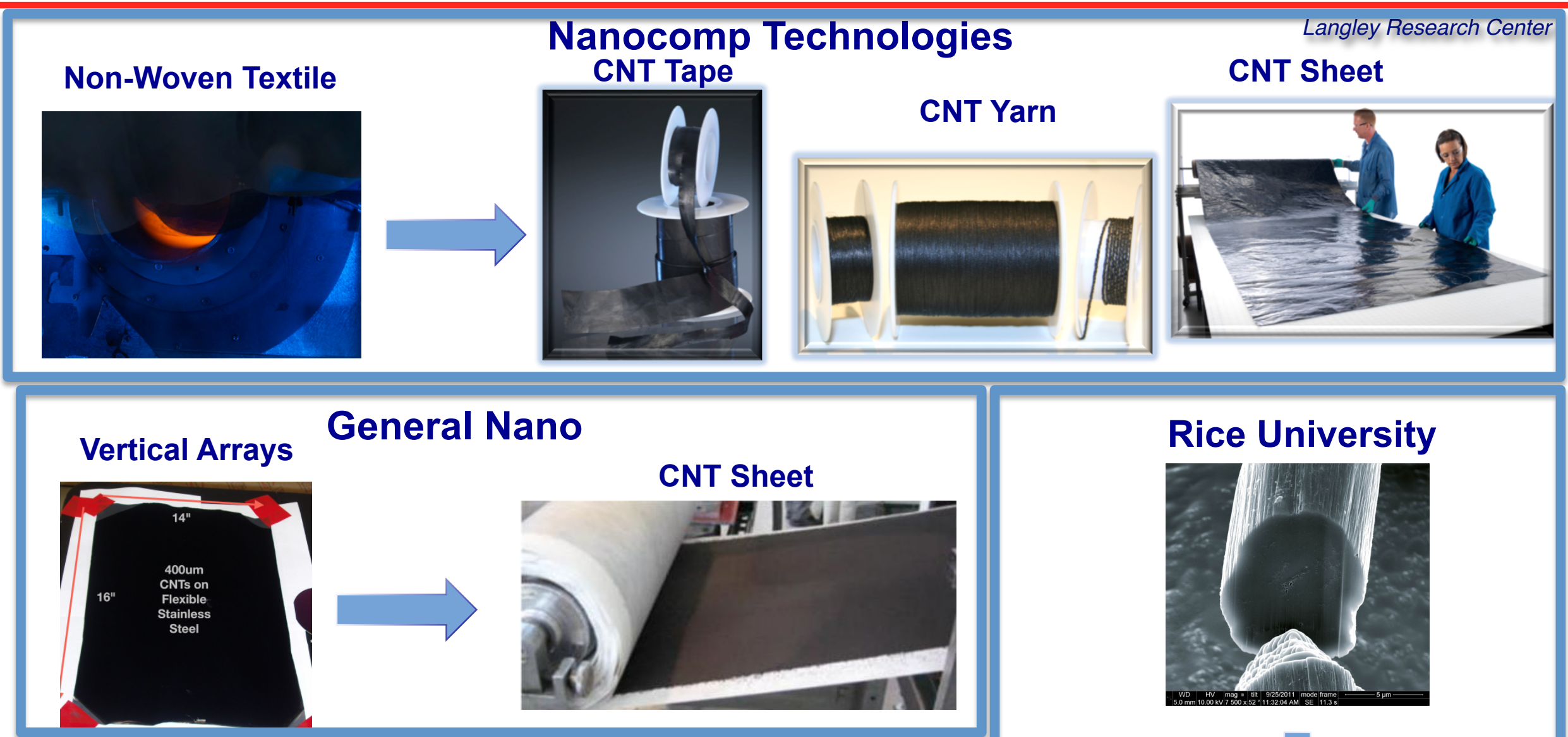

University of Cincinnati
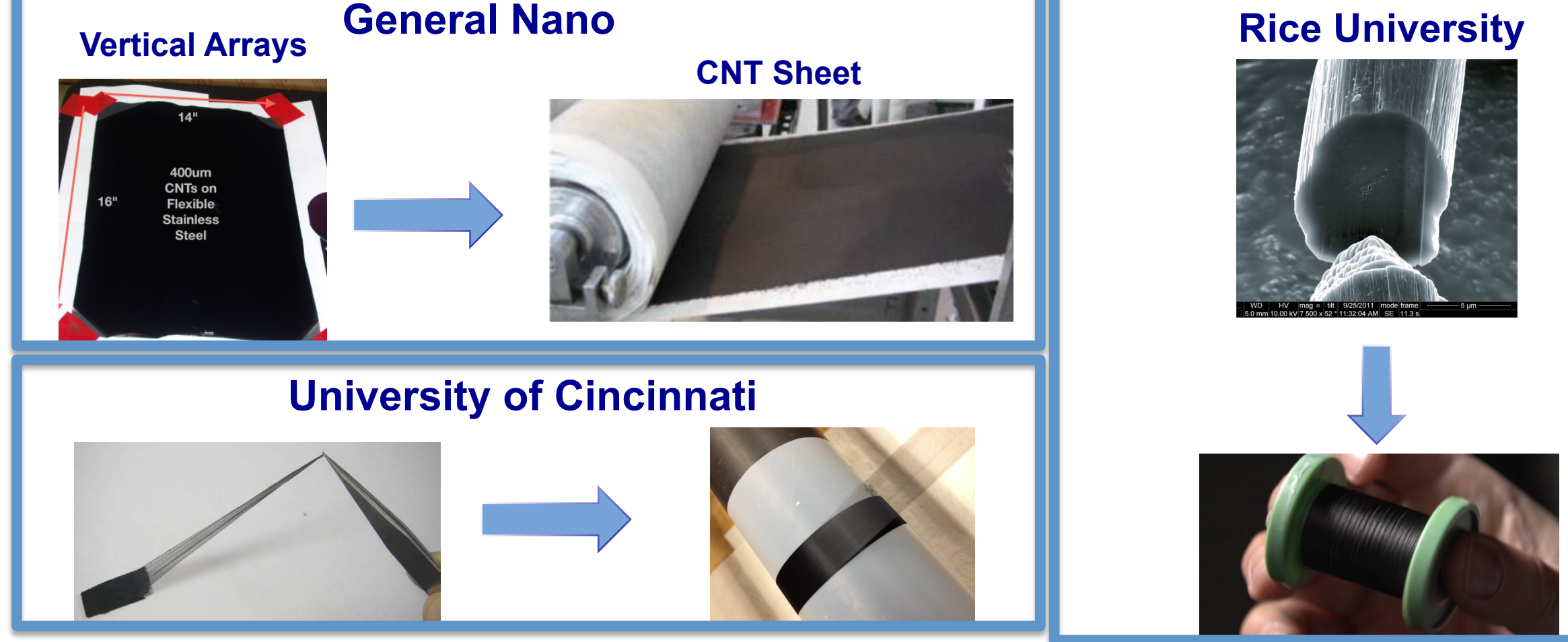


\section{Nano to Macro Challenge}

Langley Research Center

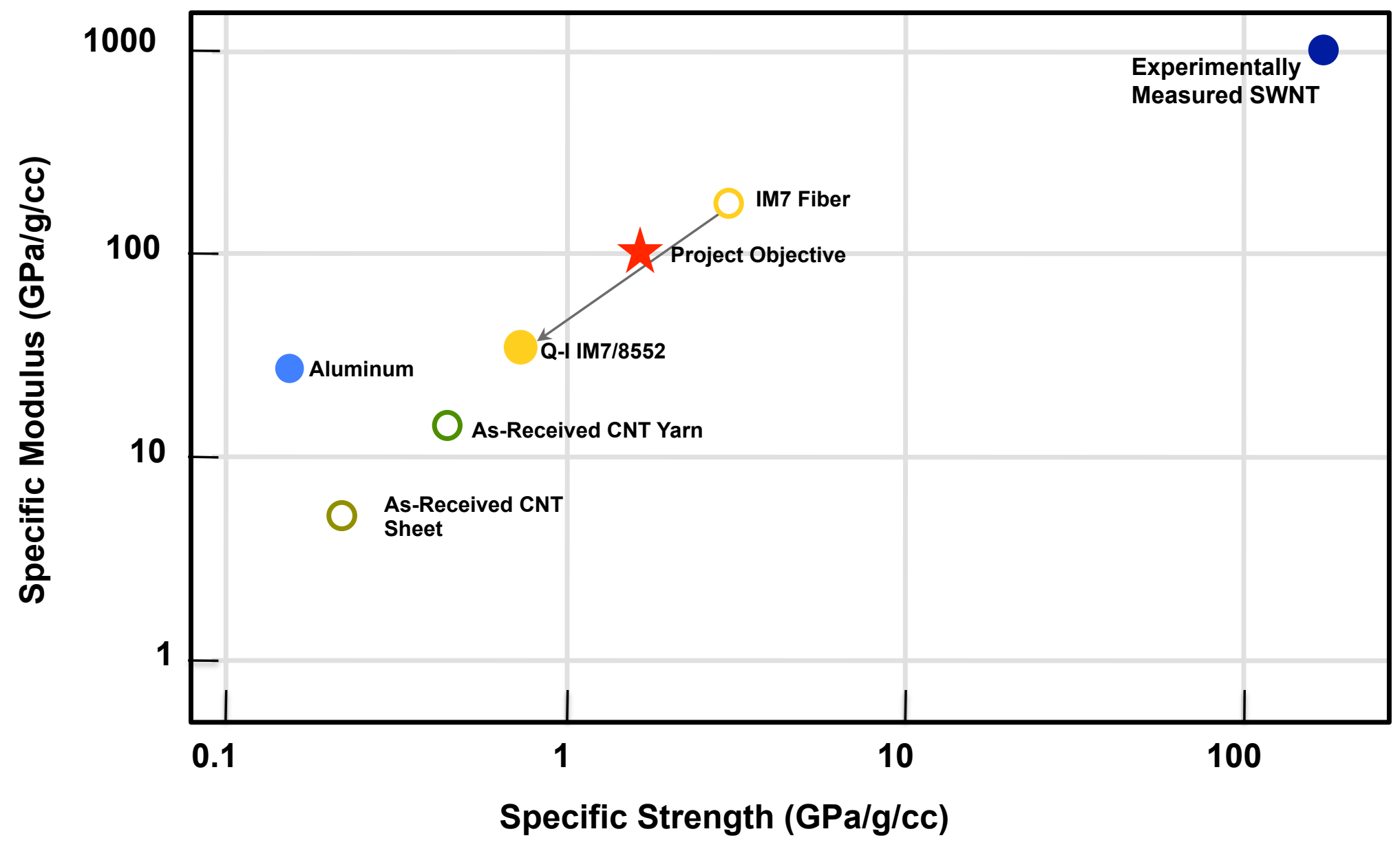

> Available materials have starting mechanical properties inferior to other SOA materials. 


\section{Computationally Guided Materials DevelopmentisA}

\section{Bundle Failure}
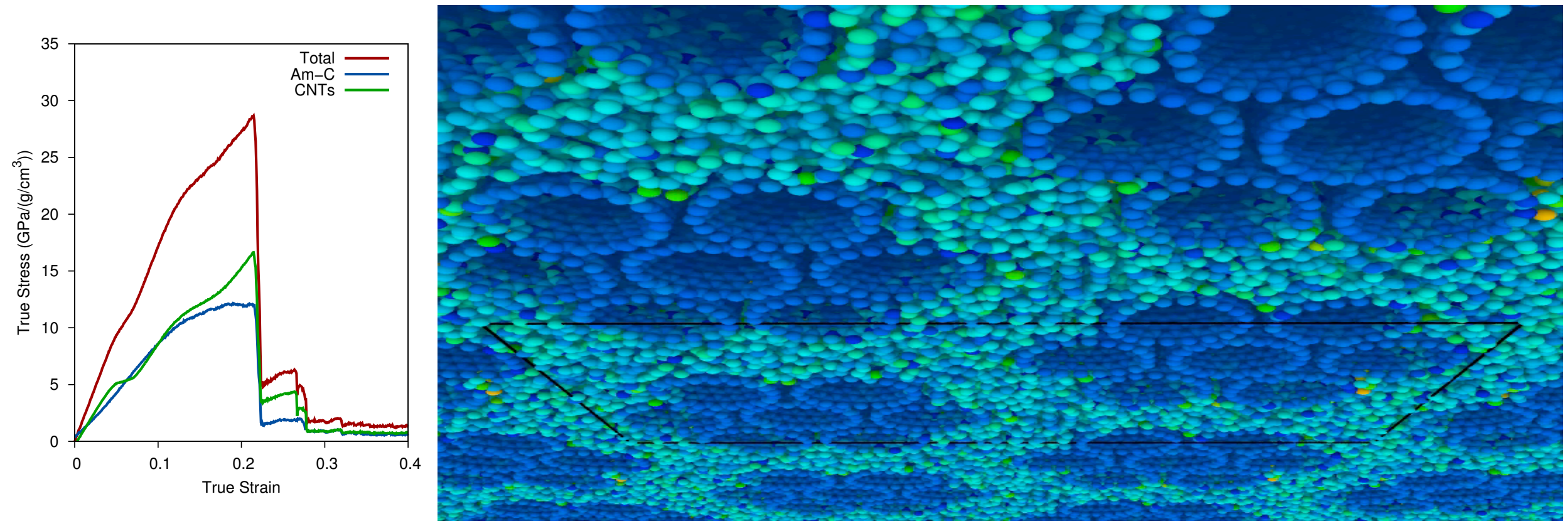


\section{Modeling CNT Based Structural MaterialswasA}

Langley Research Center

\section{Calculated Mechanical Properties in Context}

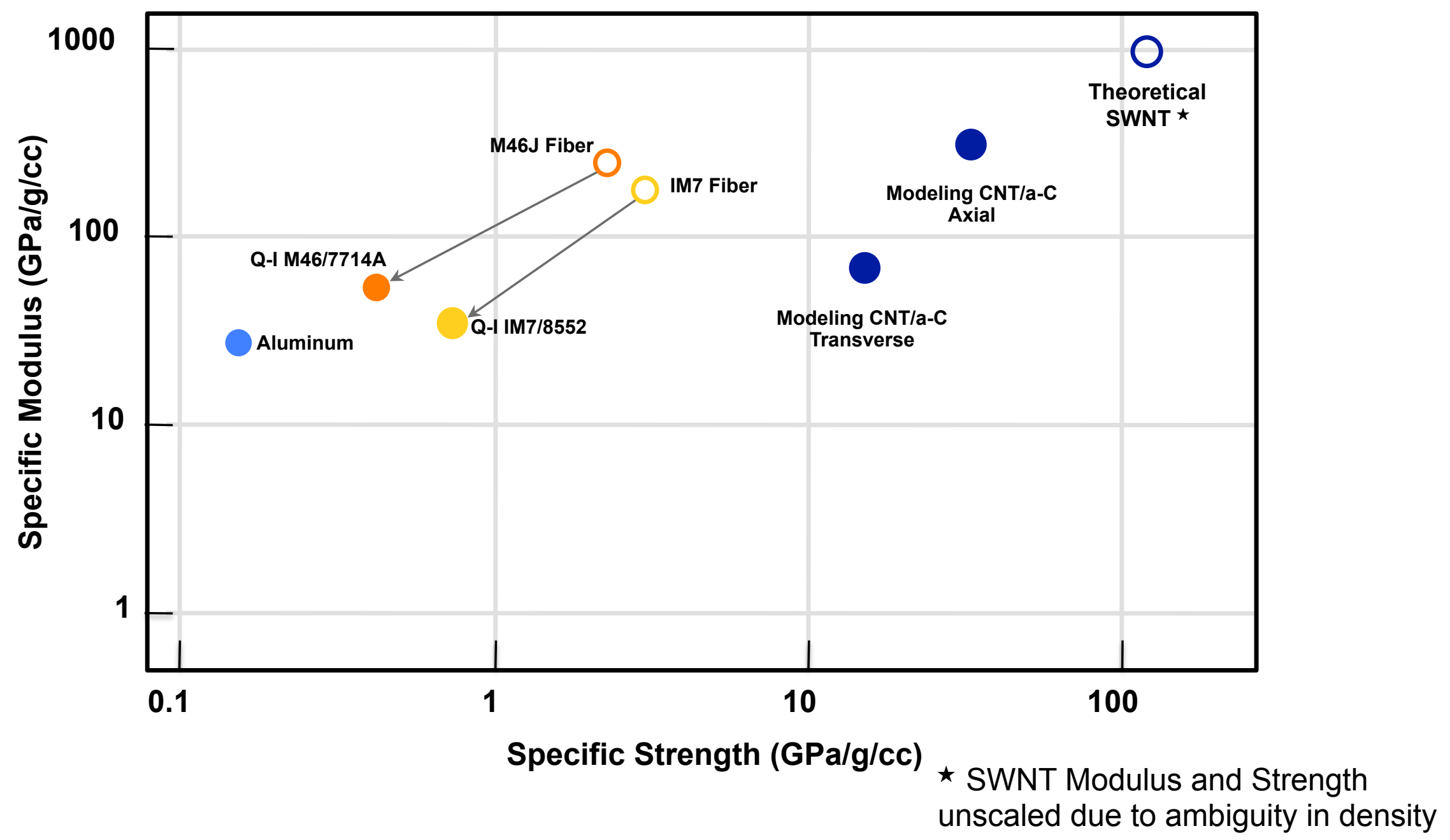




\section{CNT Composite Procedure}

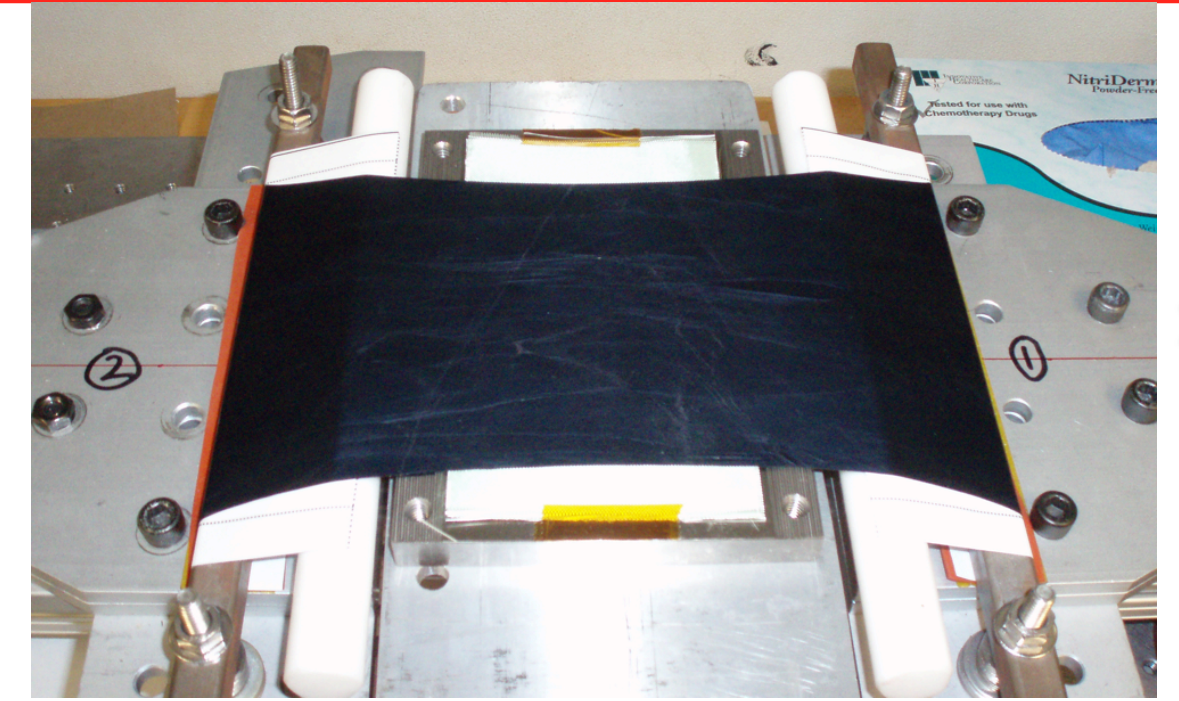

Stretched

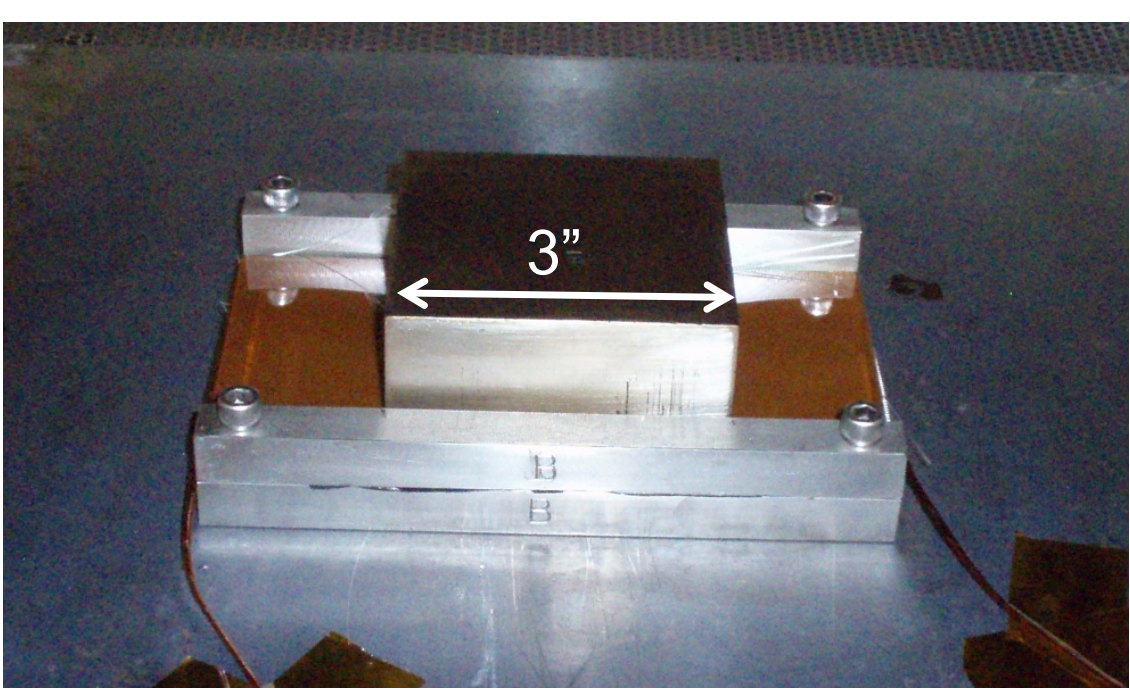

Cured while Clamped
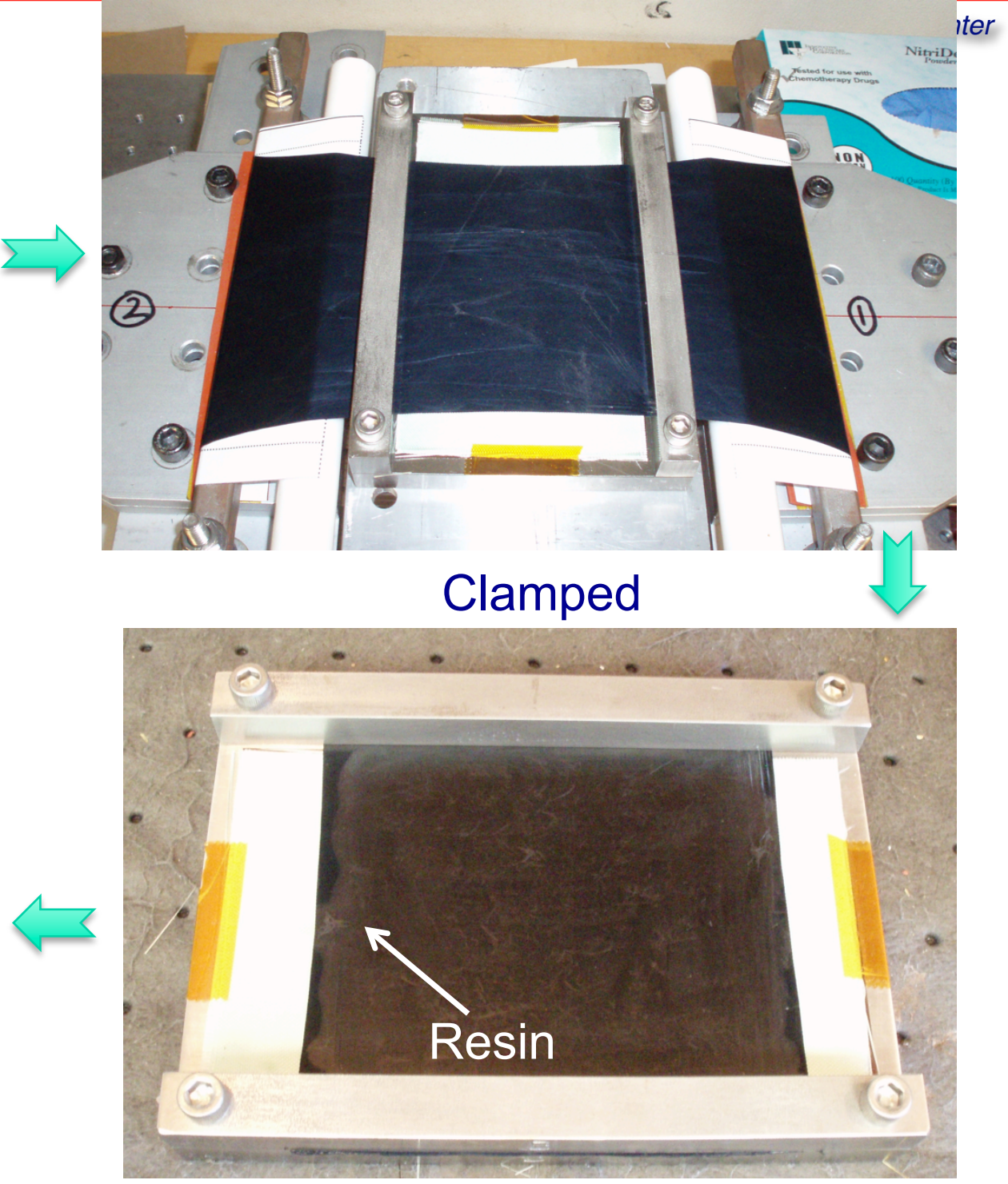

Coated with Resin Solution 


\section{CNT Composite Tensile Testing}
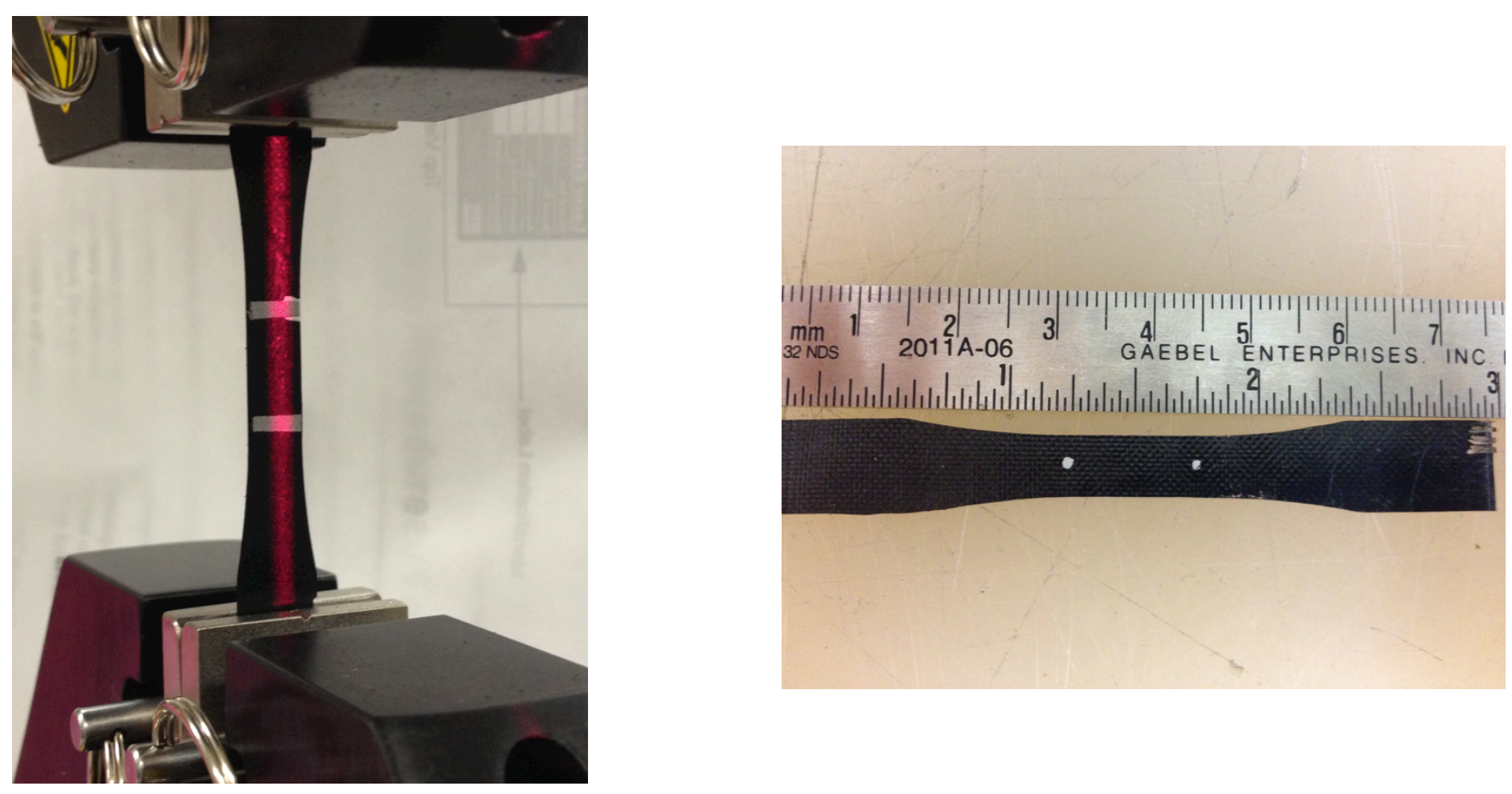


\section{Influence of Post-Processing on GNT Sheet Composite Properties}

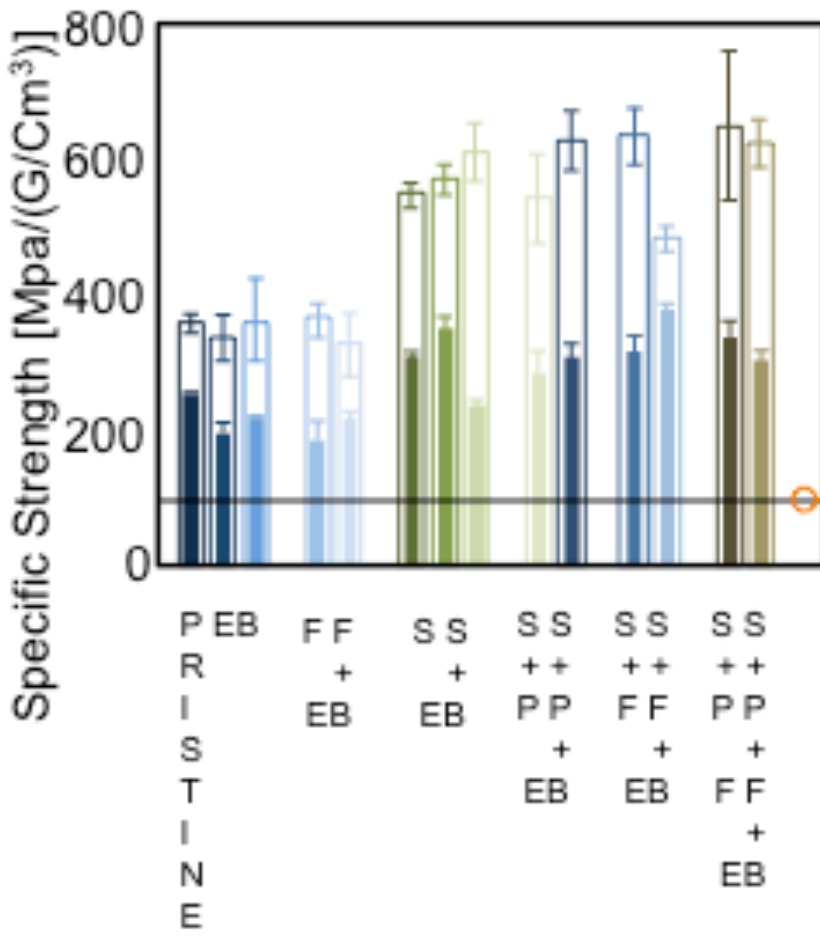

Pristine: PristineCNT sheet (Lot\#70044-Acetone treated)

EB: $\quad$ EB (40 min)

EB: $\quad E B(90 \mathrm{~min})$

$F$ : $\quad$ m-CPBA Functionalized

$\mathrm{F}+\mathrm{EB} \quad \mathrm{m}$-CPBA Functionalized +EB (90min)

S Stretched (41\%)

S + EB: Stretched $(49 \%)+E B(90 \mathrm{~min})$

EB ( $90 \mathrm{~min})$ Stretched $(20 \%)$

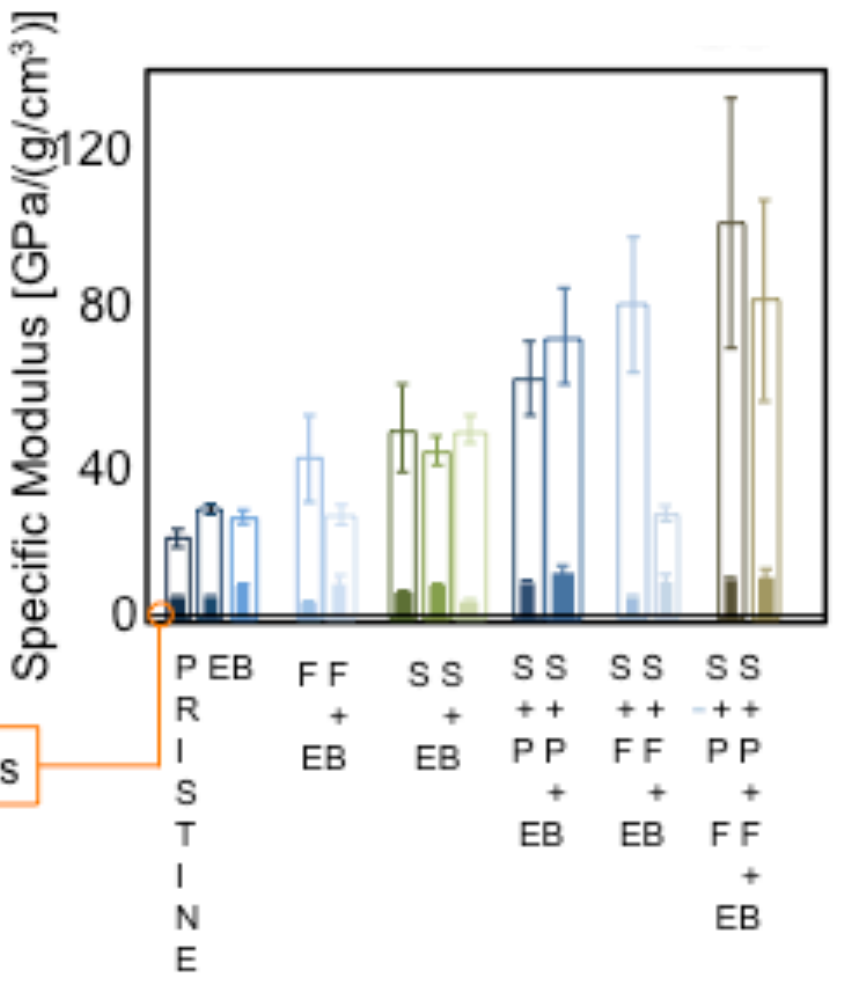

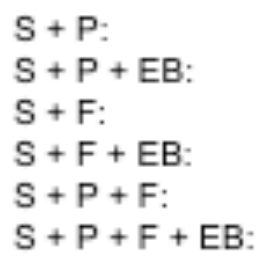




\section{GNT Yarn to GNT COPV}

NASA
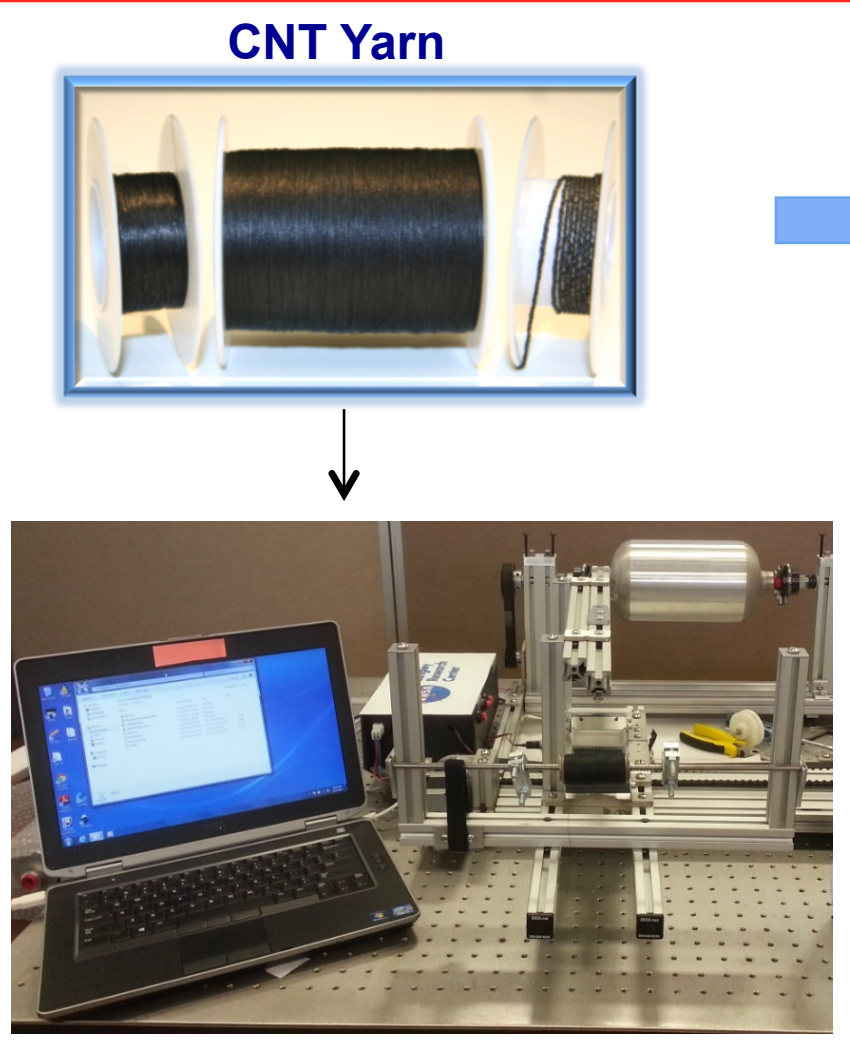

Solution Infiltration and Wet Winding of CNT Yarn
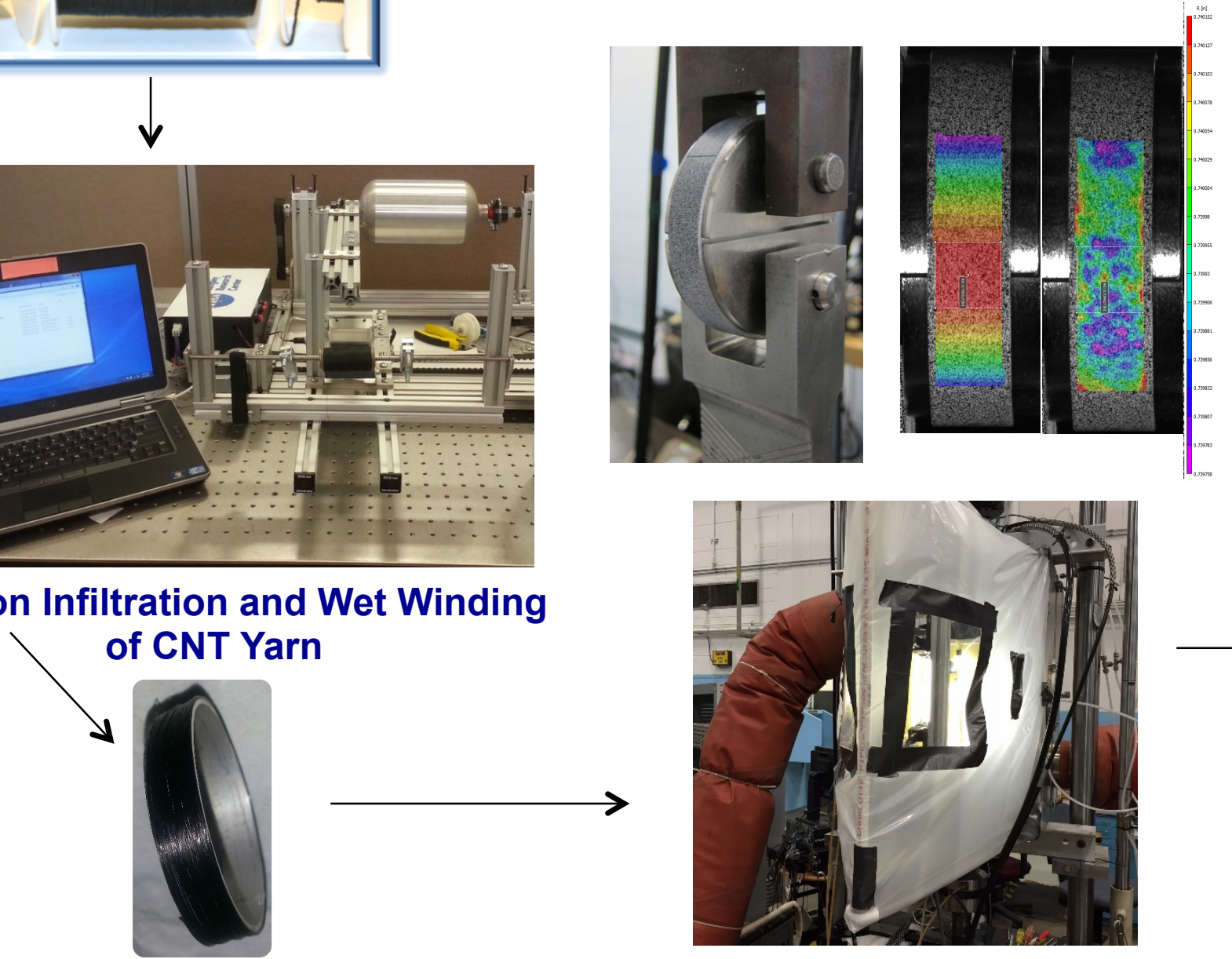

\section{CNT Yarn COPV}
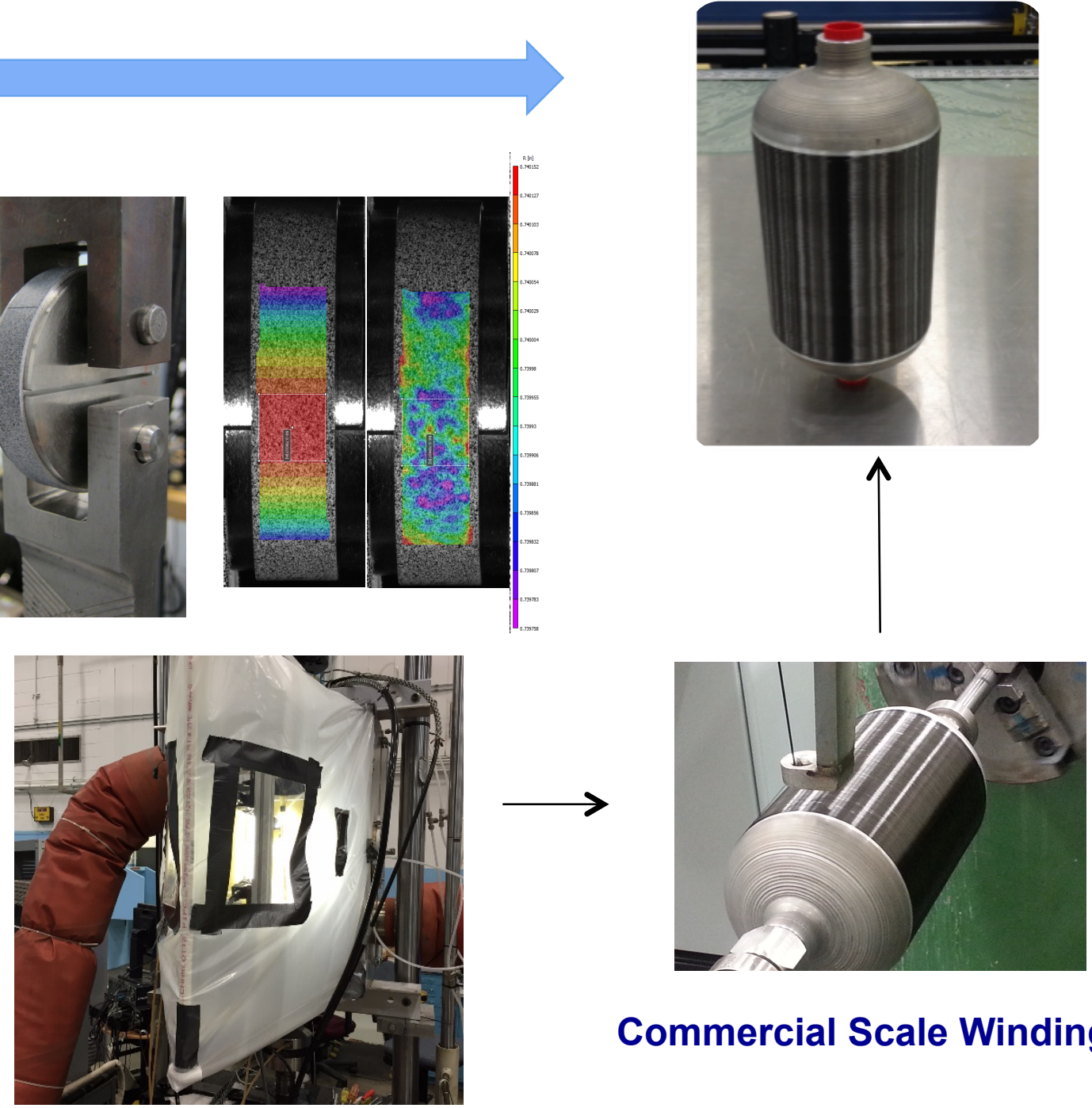

Commercial Scale Winding

Variable Temperature Mechanical Testing 


\section{Characterization of Wound CNT CompositusA}

Langley Research Center
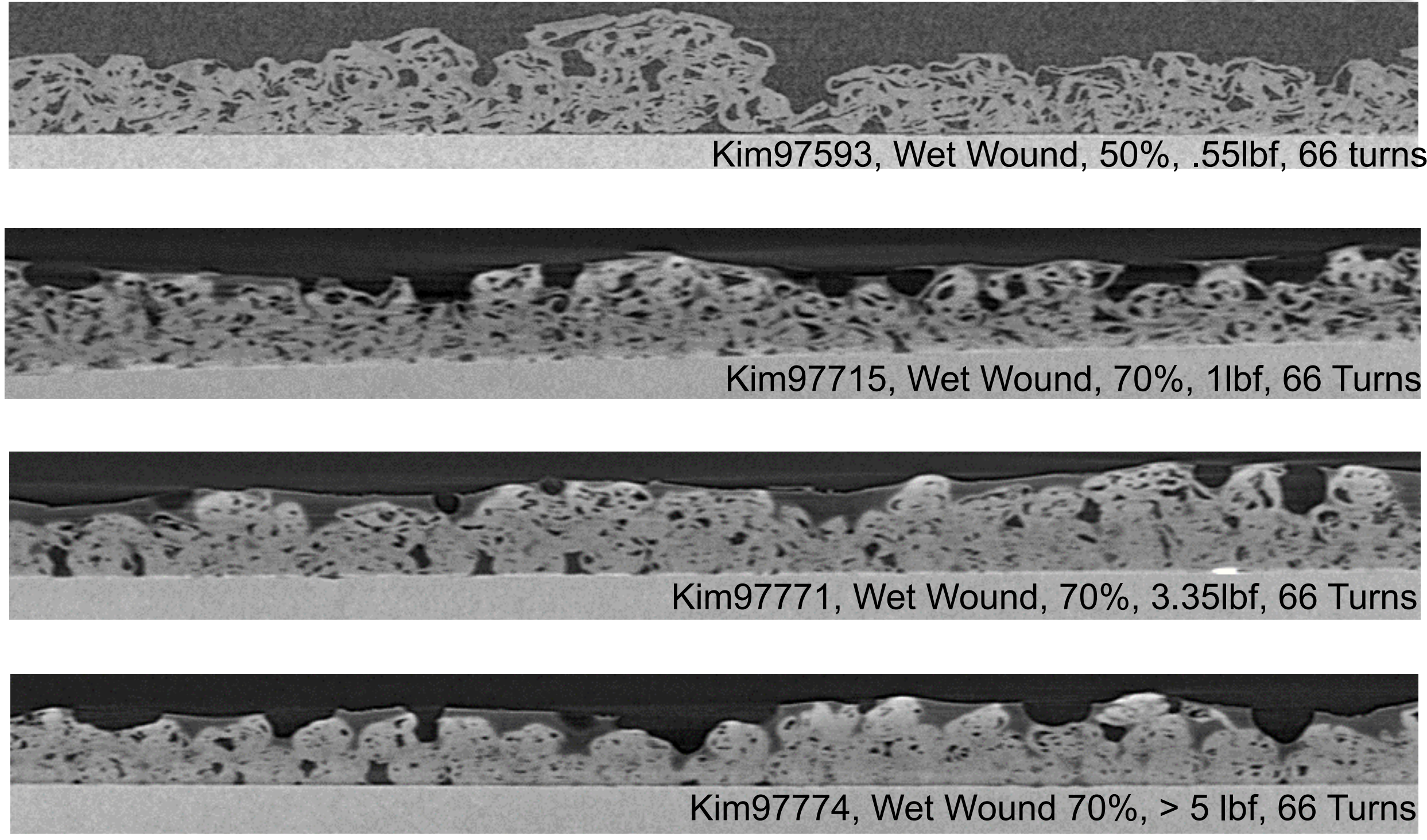


\section{Status - End of FY 14}

Langley Research Center

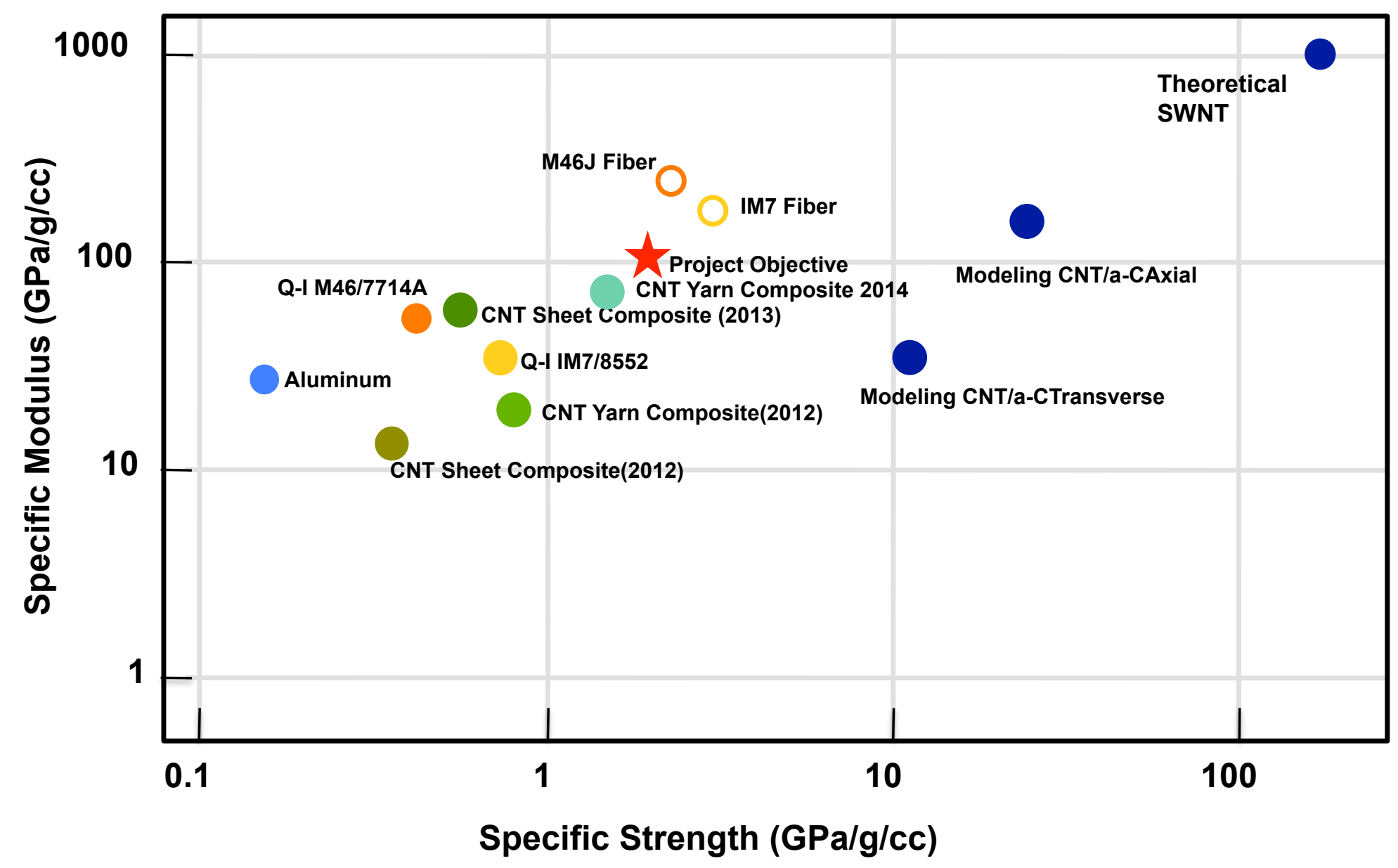




\section{How is Structural Nano Different?}

Langley Research Center

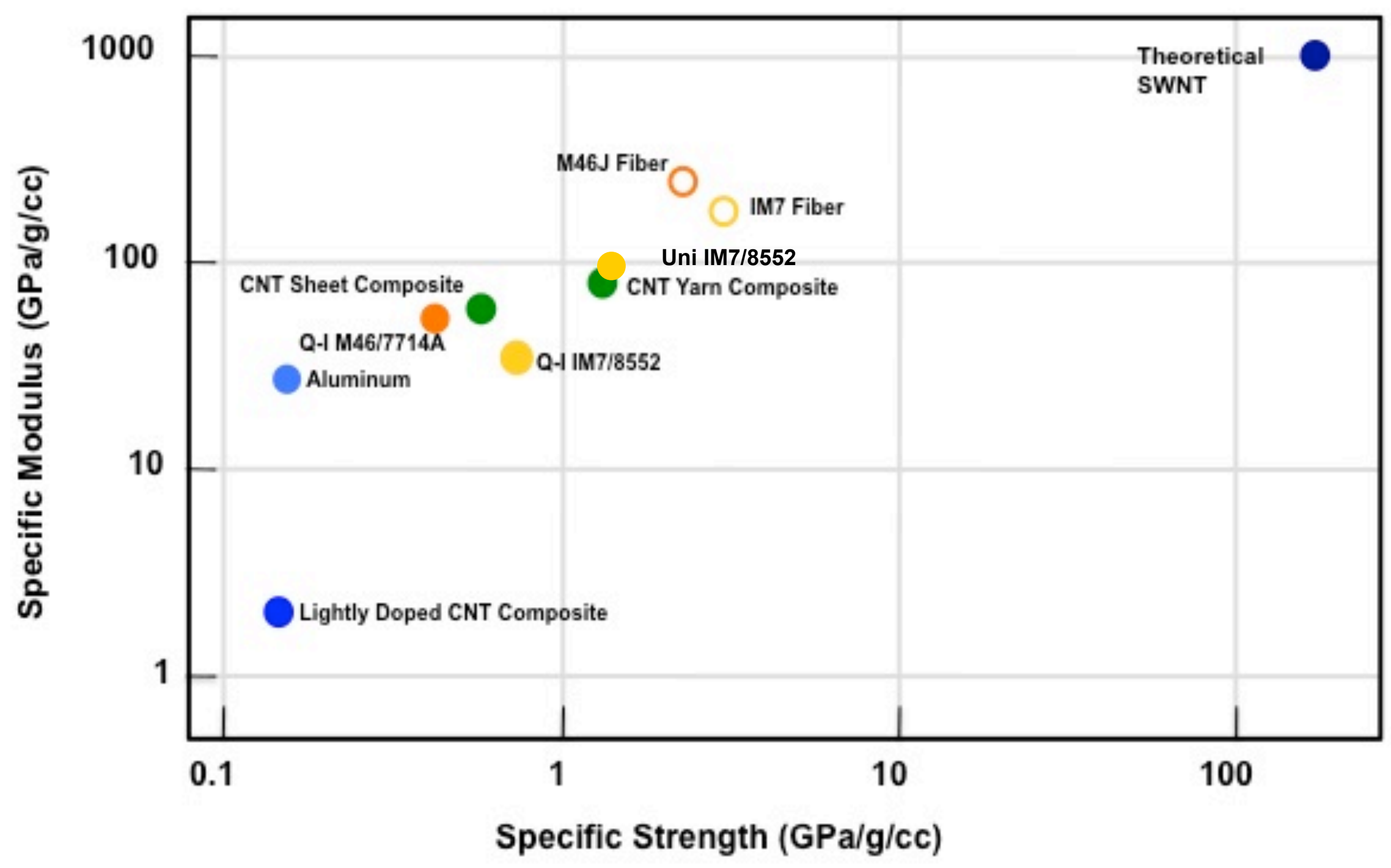




\section{Accelerated Technology Maturation}

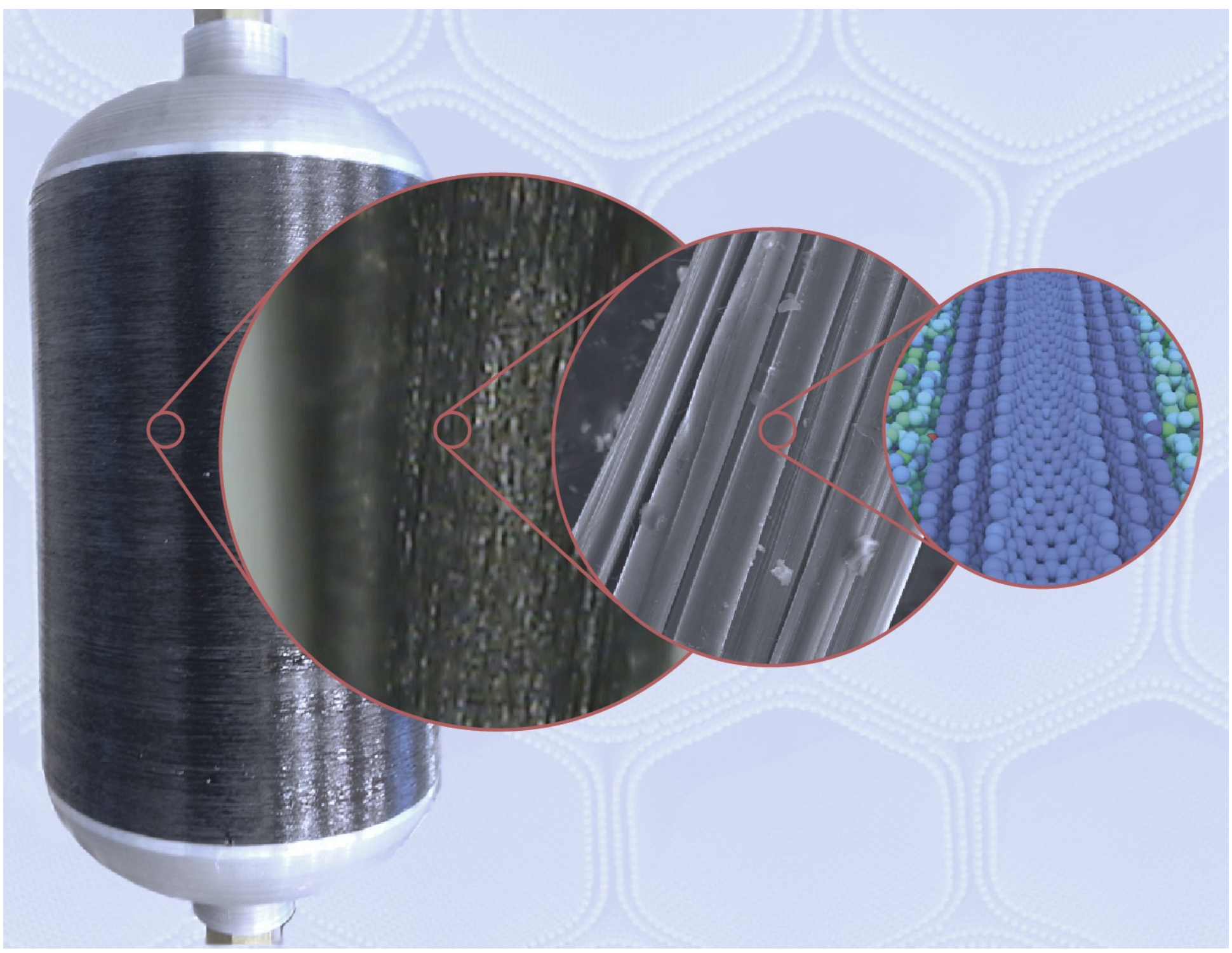




\section{Technology Tipping Point}

NASA

Langley Research Center

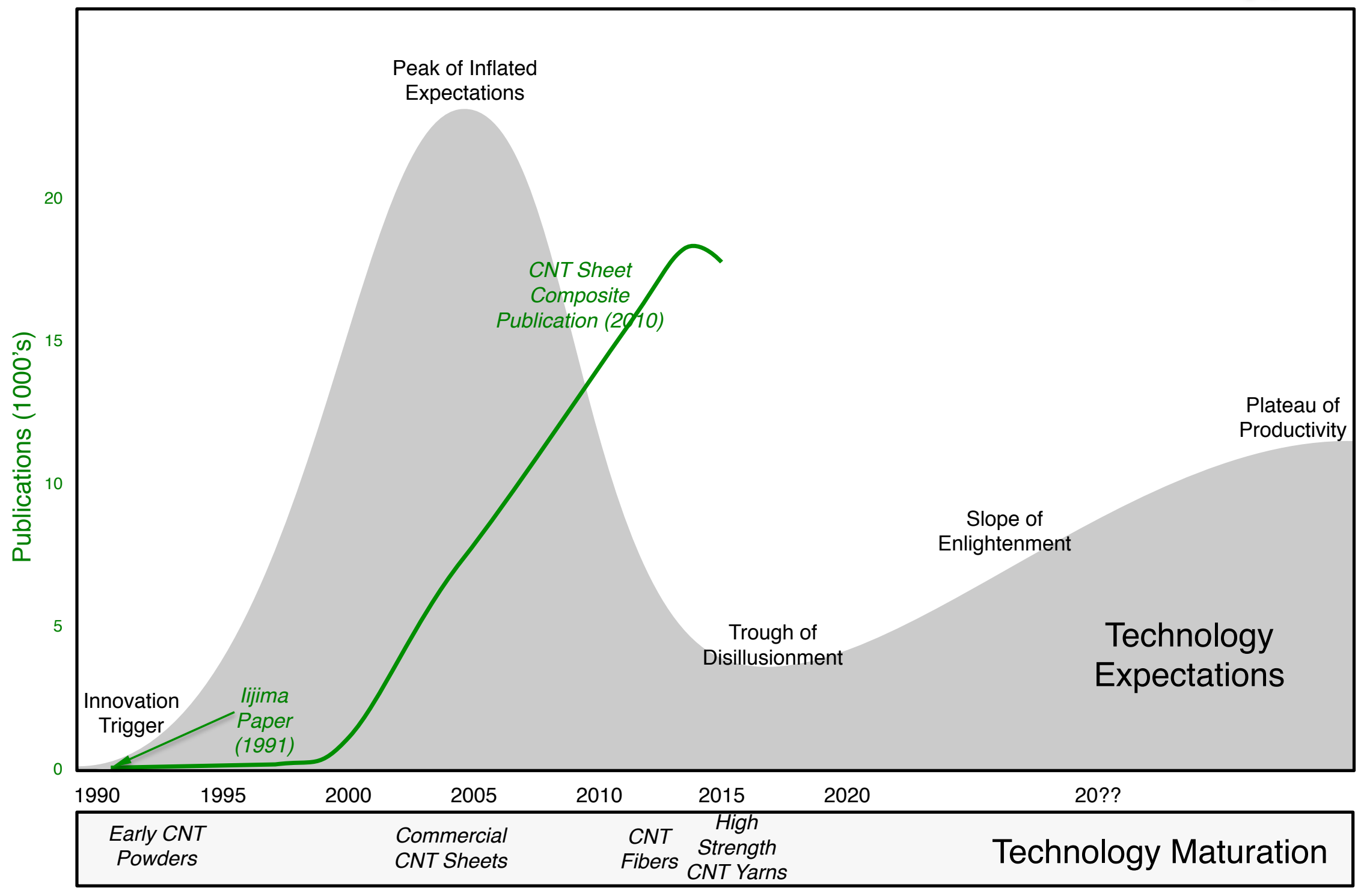




\section{CNTIAerogel Wires and Cables}

- OBJECTIVE: Reduce the mass and improve the fatigue resistance of power and data cables

- APPROACH: Utilize carbon nanotube conductors and ultralightweight aerogel insulation to reduce cable mass and improve fatigue resistance

- Employ intercalation chemistries to enhance electrical properties

- Develop processing methods to apply aerogel insulation

- Characterize electrical and thermal properties and cable durability

- IMPACT:

$>70 \%$ reduction in data cable mass

$\geq 50 \%$ reduction in power cable mass

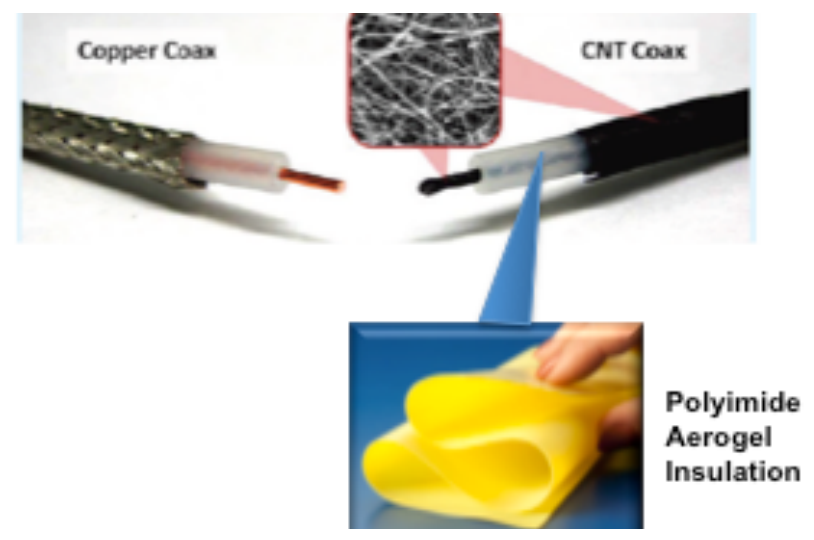

Use of carbon nanotube conductors and ultralightwieght polymer aerogel insulation could reduce the mass of data cables by $>70 \%$.

- FY2014 MAJOR ACCOMPLISHMENTS:

$\checkmark$ Improved electrical conductivity of CNT wires to $98 \mathrm{kS} / \mathrm{cm}$

$\checkmark$ Demonstrated dip coating of polyimide aerogels onto CNT wires 


\section{Accelerate Technology Maturation with Multidisciplinary Approach}

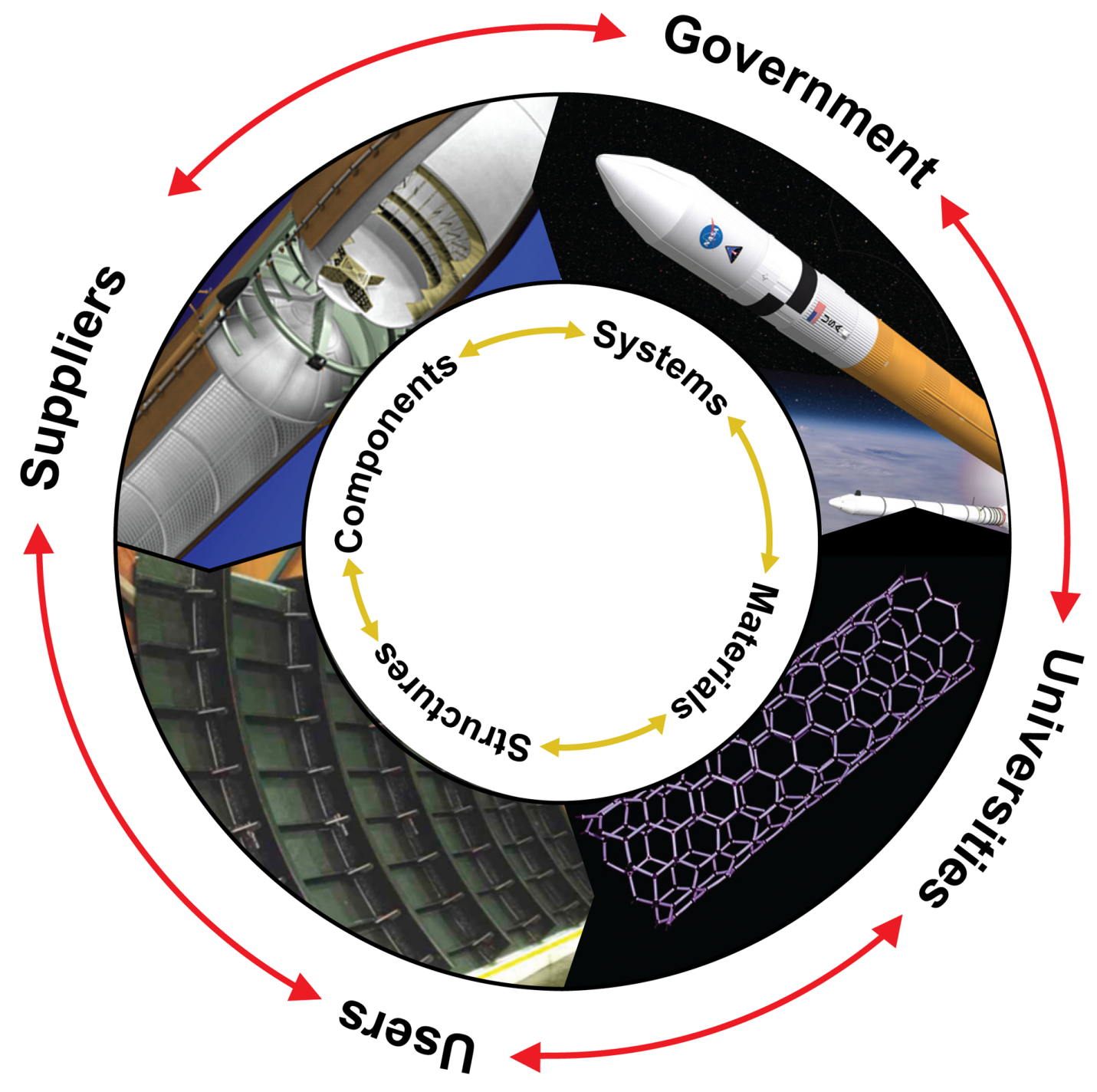




\section{Thank You}

NASA

Langley Research Center

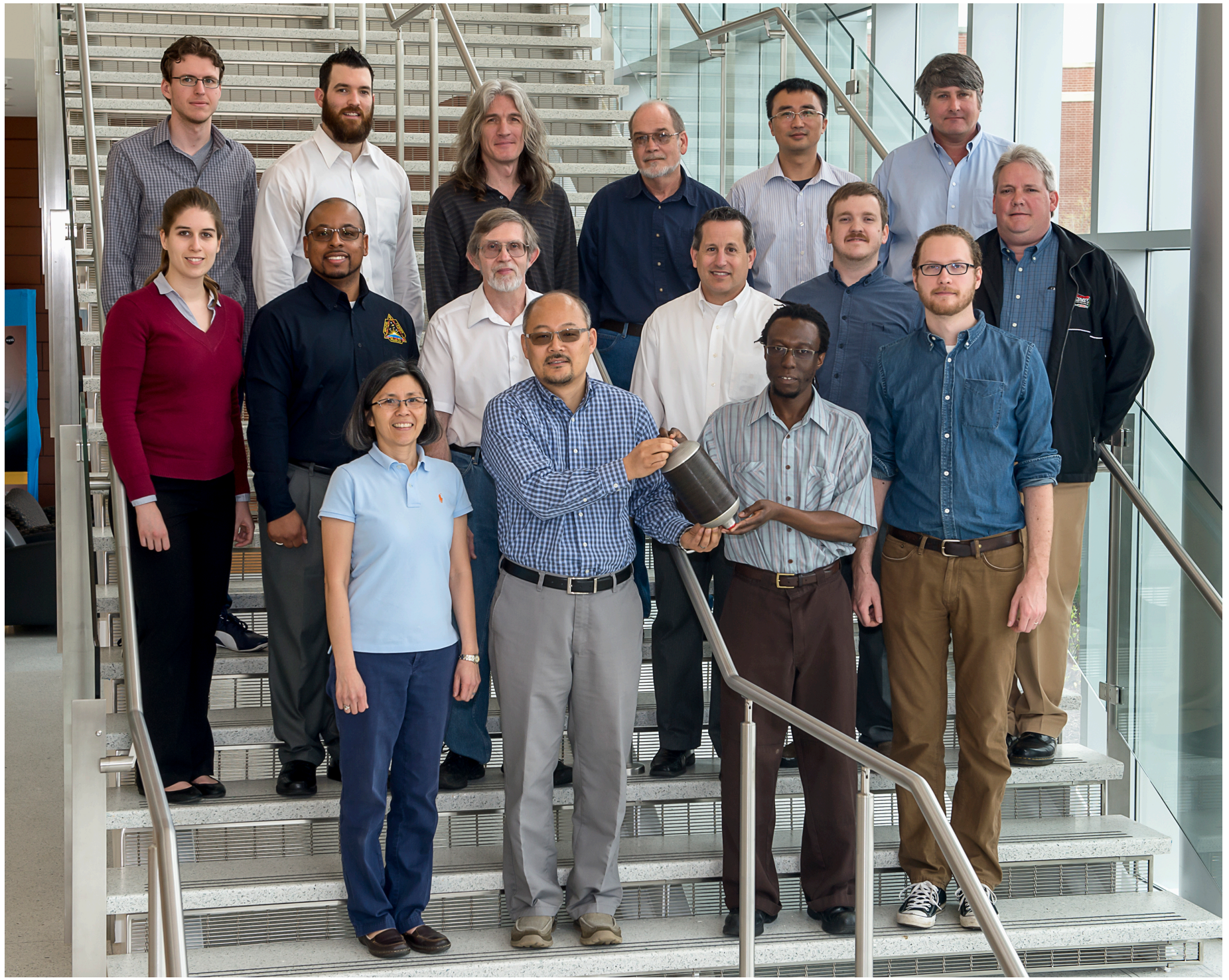

